\title{
Profound Peripheral T-Lymphocyte Depletion and Activation in Disseminated Tuberculosis
}

\author{
Denise Silva Rodrigues, Reinaldo Salomão \\ and Esper Georges Kallas
}

\author{
Infectious Diseases Division, Federal University of \\ São Paulo; São Paulo, SP, Brazil
}

\begin{abstract}
Three HIV-1-seronegative patients with disseminated tuberculosis presented significant depletion of T-cell counts, in $\mathrm{CD}_{4}^{+}$and/or $\mathrm{CD}_{8}^{+}$cells, associated with increased expression of activation marker $\mathrm{CD}_{38}$ on $\mathrm{CD}_{8}{ }^{+} \mathrm{T}$-lymphocytes. This finding raises the question of potential mechanisms involved in the activation or loss of T-cells in disseminated tuberculosis.

Key Words: Mycobacterium tuberculosis, disseminated tuberculosis, lymphocyte, cellular activation.
\end{abstract}

Tuberculosis is a major global public health problem and is still one of the leading causes of infectious-disease-related deaths. A better understanding of the mechanisms governing the host reaction to the causative pathogen and disease control is fundamental for the development of new and more immunogenic vaccines and adjunctive therapies.

It is known that the cellular immune response, particularly that produced by T-lymphocytes, plays a central role in controlling Mycobacterium tuberculosis replication [1,2]. The immune response after $M$. tuberculosis infection and disease may be visualized by the measurement of T-lymphocyte phenotypes in human peripheral blood. Diminished numbers of $\mathrm{CD}_{4}^{+}$and $\mathrm{CD}_{8}^{+} \mathrm{T}$-cells have been described in patients with active tuberculosis [3-6]. Since defense against $M$. tuberculosis depends on the efficacy of cell-mediated immunity, it is important to unravel its mechanisms $[1,2,7]$.

In a previous study, lower $\mathrm{CD}_{4}^{+}$and $\mathrm{CD}_{8}^{+} \mathrm{T}$-lymphocyte counts were found in patients with active disease. Expanded immunophenotyping demonstrated the loss of both naïve and memory/effector subpopulations of $\mathrm{CD}_{4}^{+} \mathrm{T}$-lymphocytes, and increased $\mathrm{CD}_{8}^{+} \mathrm{T}$-lymphocyte activation [8]. Here we report a profound depletion in T-cells subpopulations in patients with severe tuberculosis, in the absence of other identifiable causes of immunodeficiency.

Written informed consent was obtained from all the participants or from their legal representative, according to the guidelines of the Brazilian Ministry of Health. Three patients with disseminated tuberculosis were identified in the Infectious Diseases ward of the Hospital São Paulo, of the Federal University of São Paulo. Cases were defined by a medical history, clinical findings, and image studies compatible with miliary tuberculosis, or when multiorgan involvement was detected. Tuberculosis diagnosis was confirmed by the presence of at least one positive sputum smear for acid-fast bacilli or the growth of M. tuberculosis in a biological sample.

Received on 16 October 2005; revised 19 january 2006.

Address for correspondence: Dr. Esper Georges Kallas, M.D., Ph.D. Disciplina de Doenças Infecciosas e Parasitárias, Escola Paulista de Medicina / UNIFESP. Rua Mirassol, 207. Zip code: 04044-010 São Paulo - SP, Brazil. E-mail: kallas.dmed@epm.br

The Brazilian Journal of Infectious Diseases 2006;10(1):59-61. (C) 2006 by The Brazilian Journal of Infectious Diseases and Contexto Publishing. All rights reserved.
A flow cytometric assay was performed using a fourcolor staining panel of the conjugated antibodies: HLADR fluorescein isothiocyanate (FITC, clone L243), $\mathrm{CD}_{27}$ phycoerythrin (PE, clone L128), $\mathrm{CD}_{45}$ RA FITC (clone L48), $\mathrm{CD}_{8}$ peridin chlorophyll protein (PerCP, clone SK1), $\mathrm{CD}_{4}$ PerCP (clone SK3), and $\mathrm{CD}_{3}$ allophycocyanin (APC, clone UCHT1), monoclonal antibodies (BD Biosciences, San Jose, $\mathrm{CA}$ ), and $\mathrm{CD}_{38}$ FITC (clone HIT2, Pharmingen, San Diego, CA). Briefly, $100 \mu \mathrm{L}$ of EDTA-treated blood was incubated at room temperature with a combination of monoclonal antibodies for 15 minutes in the dark, and then treated with lysing buffer for a further 10 minutes. Cells were washed and resuspended in phosphate saline buffer supplemented with $1 \%$ sodium azide for cytometric analysis. To obtain blood $\mathrm{T}-\mathrm{CD}_{4}{ }^{+}$and $\mathrm{CD}_{8}{ }^{+}$lymphocyte absolute counts, a TriTest and TrueCount reagent kit (BD Biosciences) was used according to the manufacturer's instructions.

The subpopulation of naïve, effector, and memory cells was analyzed as a function of the absolute number and percentage of cells expressing different combinations of $\mathrm{CD}_{45} \mathrm{RA}$ and $\mathrm{CD}_{27}$ on the $\mathrm{CD}_{4}{ }^{+} \mathrm{T}$-lymphocytes. The activation of $\mathrm{CD}_{8}^{+}$T-lymphocytes was determined by surface expression of the $\mathrm{CD}_{38}$ molecule.

Three cases of HIV-negative patients with disseminated tuberculosis and pulmonary involvement were available for analysis. They had no other underlying disease and no history of immunosuppressive therapy.

Patient 1: A 51 year-old man presented with two months of symptoms of respiratory disease. He complained of chest pain, shortness of breath, and cough with productive sputum, together with four months of progressive weight loss, weakness, and intermittent fever. On physical examination the patient appeared ill and cachectic. Superficial cervical lymph nodes were palpable. Miliary infiltrates in a frontal chest roentgenogram suggested hematogenic dissemination of $M$. tuberculosis. Acid-fast bacilli were found in the sputum smear, and granulomas were found in a lymph node biopsy. The $\mathrm{CD}_{4}^{+}$and $\mathrm{CD}_{8}^{+} \mathrm{T}$ lymphocytes counts were 186 cells $/ \mu \mathrm{L}$ and 152 cells $/ \mu \mathrm{L}$, respectively.

Patient 2: A 50 year-old woman was hospitalized presenting severe respiratory involvement. She described a two- 
months of weight loss and had recently developed severe respiratory failure. A chest roentgenogram demonstrated typical miliary lesions. Acid-fast bacilli were found in the sputum smear. Her $\mathrm{CD}_{4}^{+}$and $\mathrm{CD}_{8}{ }^{+} \mathrm{T}$-lymphocyte counts were 59 cells $/ \mu \mathrm{L}$ and 43 cells $/ \mu \mathrm{L}$, respectively. She died a few days after hospital admittance.

Patient 3: A 31 year-old man was admitted with a history of weight loss and productive cough during the previous three months. He developed headache and confusion a few weeks before hospital admission. He presented with enlarged bilateral cervical lymph nodes and left brachial hemiparesis, and the head CT scan revealed a large thalamic ischemia. The chest roentgenograms revealed several cavitated lesions and diffuse infiltrates. A sputum smear and the lymph node biopsy revealed acid-fast bacilli and granulomas. Cerebral spinal fluid culture was negative for M. tuberculosis. The $\mathrm{CD}_{4}^{+}$and $\mathrm{CD}_{8}^{+}$T-lymphocyte counts were 514 cells $/ \mu \mathrm{L}$ and 53 cells $/ \mu \mathrm{L}$, respectively.

Two of the patients presented with $\mathrm{CD}_{4}^{+} \mathrm{T}$-lymphocyte absolute counts below 300 cells $/ \mu \mathrm{L}$. A severe depletion of the naïve, effector and memory subpopulations associated with low numbers of $\mathrm{CD}_{8}^{+}$T-lymphocytes was observed in all three patients with disseminated tuberculosis, coupled with higher expression of $\mathrm{CD}_{38}{ }^{+}$on the $\mathrm{CD}_{8}{ }^{+} \mathrm{T}$-lymphocytes than in patients with pulmonary tuberculosis and in healthy controls (Table 1).

\section{Discussion}

Several studies have demonstrated that tuberculosis can exert a significant impact on lymphocyte counts $[3,4,6,9]$. Swaminathan et al. compared healthy, tuberculinpositive children to those with tuberculosis and found reduced circulating CD4+ T-cell counts in the sick children, which reversed after tuberculosis therapy [8].

In our cohort of 71 subjects, we observed a significant reduction of T-lymphocyte counts in those with active tuberculosis, when compared to healthy subjects [8]. This difference was reversed after treatment, further supporting the possibility that the disease itself might be responsible for the observed T-cell depletion. In addition, a significant decrease in absolute T-lymphocyte $\mathrm{CD}_{4}^{+}$counts, distributed among naïve, effector and memory subpopulations, was observed in patients with disseminated tuberculosis. The significant $\mathrm{CD}_{4}$ and $\mathrm{CD}_{8}$ T-cell depletion in these three patients resembles found in tuberculosis patients with AIDS [10]. One study with $430 \mathrm{HIV}$-seronegative tuberculosis patients conducted in Dakar, Senegal, associated low peripheral $\mathrm{CD}_{4}^{+} \mathrm{T}$-cell counts with severe disease, most patients presenting extrapulmonary involvement, miliary dissemination, oral candidiasis, and low level tuberculin reaction [11].

It has been demonstrated that $\mathrm{CD}_{8}^{+} \mathrm{T}$-lymphocytes have cytolytic activity against the tuberculosis bacillus [12], and their deficiency can result in susceptibility to infection by $M$. tuberculosis [13]. However, the exact function of these cells in host defense remains controversial. Therefore, the understanding of the activation status of such cells may help determine their role in disease pathogenesis. We came across substantial cellular activation in the three patients with disseminated tuberculosis, significantly higher that the previously observed cellular activation in patients with localized disease [8].

These findings should impact the clinical and laboratory evaluation of patients with disseminated tuberculosis. The awareness of the profound depletion of T-cell subpopulations associated with severe disease may indicate misinterpreted idiopathic T-lymphocytopenia or other cellular immunodeficiencies.

A laboratory follow-up is mandatory to distinguish the effects of active disease from an underlying immunodeficiency. The marked cellular activation seen in these patients could mean that $\mathrm{CD}_{38}$ expression would be a useful marker of tuberculosis activity and prognosis.

Table 1. Absolute $\mathrm{CD}_{4}^{+}$and $\mathrm{CD}_{8}^{+} \mathrm{T}$-lymphocyte numbers and activation of $\mathrm{CD}_{8}^{+} \mathrm{T}$-cells, measured by $\mathrm{CD}_{38}$ surface expression

\begin{tabular}{|c|c|c|c|}
\hline & $\begin{array}{c}\text { Total } \mathrm{CD}_{4}{ }^{+} \mathrm{T}- \\
\text { lymphocytes, cells } / \mu \mathrm{L}\end{array}$ & $\begin{array}{c}\text { Total } \mathrm{CD}_{8} \mathrm{~T} \\
\text { lymphocytes, cells/ } \mu \mathrm{L}\end{array}$ & $\begin{array}{c}\text { Percentage of } \mathrm{CD}_{38}{ }^{+} \text {in } \\
\mathrm{CD}_{8}{ }^{+} \mathrm{T} \text {-lymphocytes }\end{array}$ \\
\hline Patient \#1 & 186 & 152 & 54.88 \\
\hline Patient \#2 & 59 & 43 & 70.78 \\
\hline Patient \#3 & 514 & 53 & 58.27 \\
\hline Pulmonary TB*, median (IQR) & $690(526-857)$ & $355(240-482)$ & $49.76(34-60)$ \\
\hline Treated TB*, median (IQR) & $830(738-969)$ & $469(323-534)$ & $29.20(22-38)$ \\
\hline Healthy controls*, median (IQR) & $1153(997-1291)$ & $830(602-830)$ & $39.04(31-47)$ \\
\hline
\end{tabular}

IQR: Interquartile range. *: Reference values for pulmonary tuberculosis (TB); treated TB, and healthy controls were obtained from Rodrigues et al. [8]. 


\section{References}

1. Cooper A.M., Dalton D.K., Stewart T.A., et al. Disseminated tuberculosis in interferon gamma gene-disrupted mice. J Exp Med 1993;178(6):2243-7.

2. Kaufmann S.H. How can immunology contribute to the control of tuberculosis? Nat Rev Immunol 2001;1(1):20-30.

3. Beck J.S., Potts R.C., Kardjito T., Grange J.M. T4 lymphopenia in patients with active pulmonary tuberculosis. Clin Exp Immunol 1985;60(1):49-54.

4. Onwubalili J.K., Edwards A.J., Palmer L. T4 lymphopenia in human tuberculosis. Tubercle 1987;68(3): 195-200.

5. Singhal M., Banavalikar J.N., Sharma S., Saha K. Peripheral blood T-lymphocyte subpopulations in patients with tuberculosis and the effect of chemotherapy. Tubercle 1989;70(3):171-8.

6. Jones B.E., O M.M., Taikwel E.K., et al. CD4 cell counts in human immunodeficiency virus-negative patients with tuberculosis. Clin Infect Dis 1997;24(5):988-91.

7. McDyer J.F., Hackley M.N., Walsh T.E., et al. Patients with multidrug-resistant tuberculosis with low CD4+ T-cell counts have impaired Th1 responses. J Immunol 1997; 158(1):492-500.
8. Rodrigues D.S., Medeiros E.A., Weckx L.Y., et al. Immunophenotypic characterization of peripheral Tlymphocytes in Mycobacterium tuberculosis infection and disease. Clin Exp Immunol 2002;128(1):149-54.

9. Swaminathan S., Nandini K.S., Hanna L.E., et al. T-lymphocyte subpopulations in tuberculosis. Indian Pediatr 2000;37(5):489-95.

10. Kallas E.G., Salomao R. Distribution of naive and memory/ effector CD4 + T-lymphocytes and expression of CD38 on CD8 + T-lymphocytes in AIDS patients with tuberculosis. Braz J Infect Dis 2003;7(2):161-5.

11. Kony S.J., Hane A.A., Larouze B., et al. Tuberculosis-associated severe CD4+ T-lymphocytopenia in HIV-seronegative patients from Dakar. SIDAK Research Group. J Infect 2000;41(2):167-71.

12. Lalvani A., Brookes R., Wilkinson R.J., et al. Human cytolytic and interferon gamma-secreting CD8+ T-lymphocytes specific for Mycobacterium tuberculosis. Proc Natl Acad Sci U S A 1998;95(1):270-5.

13. Flynn J.L., Goldstein M.M., Triebold K.J., et al. Major histocompatibility complex class I-restricted T-cells are required for resistance to Mycobacterium tuberculosis infection. Proc Natl Acad Sci U S A 1992;89(24):12013-7. 